\title{
Extraction and Characterization of Collagen from Buffalo Skin for Biomedical Applications
}

\author{
MOUSTAFA A. RIZK ${ }^{1,2, *}$ and NASSER Y. MOSTAFA ${ }^{2,3}$ \\ ${ }^{1}$ Chemistry Department, Faculty of Science \& Arts-sharourah, \\ Najran University, Sharourah, Saudi Arabia. \\ ${ }^{2}$ Chemistry Department, Faculty of Science, Suez Canal University, Ismailia 41522, Egypt. \\ ${ }^{3}$ Chemistry Department, Faculty of Science, Taif University, Taif- 888, Saudi Arabia. \\ ${ }^{*}$ Corresponding author E-mail: moustafarizk@yahoo.com \\ http://dx.doi.org/10.13005/ojc/320336
}

(Received: February 09, 2016; Accepted: March 15, 2016)

\begin{abstract}
Collagen is widely used for biomedical and pharmaceutical applications due to its excellent biocompatibility, biodegradability and weak antigenicity. However, applicability is limited due to its high cost and probability of disease transmission from the current sources, which are bovine and porcine. In the present study, collagen was extracted from 6 months buffalo skins as alternative save sources. Collagen was characterized by different physico-chemical techniques like ATR-FTIR, Raman, SEM, DSC and amino acids analysis. Proline and hydroxyproline contents of buffalo skin collagen were higher than those of calf skin collagen. Thermal stability of buffalo skin collagen is high with respect to that of calf skin collagen. The obtained buffalo skin collagen shows higher stiffness upon cross-linking with glutaraldehyde. Thus buffalo skin collagen can be used for fabrication of high strength bioactive sponge and sheets for medical applications, like scaffold for tissue engineering, drug delivery and wound dressing system.
\end{abstract}

Keywords: Buffalo skin; acid soluble collagen; amino acid contents; thermal stability; FTIR.

\section{INTRODUCTION}

Collagen is most widespread protein in the body occurring in most connective tissues as skin, tendon and bone ${ }^{1,2}$. Collagen consists of three parallel polypeptide strands in a left-handed, polyproline II-type helical conformation coil about each other with a one-residue stagger to form a right-handed triple helix. Collagen, a right-handed triple helix, is unique in its ability to form insoluble fibers that have high tensile strength. Twentynine different types of collagen composed of at least 46 distinct polypeptide chains have been identified in vertebrates ${ }^{3,4}$. Collagens type I, II and III are the most abundant and well investigated for biomedical applications ${ }^{5}$. Type I collagen has been described as a natural scaffold and a potential candidate for tissue engineering and reconstructive medicine ${ }^{6}$. Type I collagen is exists as triple helix. The helices have the typical repeats for collagen 
Gly-X-Y (where $X$ and $Y$ are mainly proline and hydroxyproline, respectively). Thus, proline and hydroxyproline constitute about $23 \%$ of the total protein sequence ${ }^{7}$. Collagen does not express antigenicity in physiological conditions, it is completely resorbable in vivo and its physicochemical properties can be suitably controlled. Because of its unique biological and functional properties, collagen has been widely applied in food, cosmetic, base for smart hydrogels and medicine ${ }^{8-13}$. At the present there is wide interest in collagen as biomaterials. It is most frequent used as hard and soft capsules, microspheres, sealants for vascular prostheses, wound dressing, drug delivery agent and three-dimensional tissue scaffold in tissue engineering ${ }^{11,12,14,15}$ Collagen is used in tissue engineering as scaffolds in three forms. The first form is the collagen gel system ${ }^{16,17}$. The second form of collagen scaffold is the nanofiber sheets ${ }^{18,19}$. The third form of collagen scaffold is the nanocomposites with inorganic phases like calcium phosphate mineral ${ }^{20-23}$. The main disadvantage of collagen as a material is the poor mechanical properties, which limit its applications. Collagen intended for long-term biomedical use must be modified with chemical or physical cross-linking, which improves each of thermal stability, mechanical stability and degradation rate ${ }^{24}$. Most physical methods is not high enough to fulfill the demands of tissue engineering ${ }^{25}$. Glutaraldehyde is by far the most widely used chemical cross-linking agent, due to its efficiency of stabilization of collagen-based biomaterials. The cross-linking reaction occurs between the aldehyde groups of glutaraldehyde and the free amino groups of collagen lysine or hydroxyl lysine residues ${ }^{26}$.

Commercial collagen used for biomedical applications is extracted mainly from the skin of pig and bovine ${ }^{27-29}$. However, the outbreak of prion diseases, such as bovine spongiform encephalopathy, has resulted in anxiety among users of collagen derived from these land animals. In addition, collagen extracted from bovine is prohibited for Muslim and Jewish due to religious reasons. Thus, the interest in safer sources of collagen including less velerninable animals has greatly increased. Water buffalo (Bubalus bubalis) are a traditional farm animal. They are used as the main source of red meat in many countries.
The goal of this study is to extract and characterize buffalo skin collagen to evaluate its use as a source for biomedical implantable collagen. Chemical and thermal properties of buffalo skin collagen were investigated. Mechanical properties of buffalo skin modified with GA solutions at different concentrations were also investigated.

\section{MATERIALS}

Six-month-old buffalo skin removed 2-3 $\mathrm{h}$ after slaughter was obtained from Thamarat AlQassim Company for meat production, Buraidah, Al-Qassim, Saudi Arabia. The skin was frozen until used.

All chemicals used in the present investigation were of AR Grade. Sodium hydroxide $(\mathrm{NaOH})$, Sodium Chloride $(\mathrm{NaCl})$ and tris(hydroxymethyl) aminomethane $\left(\left(\mathrm{HOCH}_{2}\right)_{3} \mathrm{CNH}_{2}\right)$ were purchased from Sigma-Aldrich. Solvents used are in analytical grade quality include Acetic acid and Butyl alcohol from Sigma-Aldrich. Hydrochloric acid solution from Merck was used for amino acid analysis.

\section{METHOD}

\section{Conditioning of the skin before collagen extraction}

A piece of the frozen skin was thawed, hairs was shaved with razor blades. The skin was washed with chilled water several times and cut into small chips with scissors.

\section{Extraction of collagen from buffalo skin}

The collagens were extracted by the method described by Kukhareva ${ }^{30}$ with a slight modification. All the extraction procedures were performed at $4{ }^{\circ} \mathrm{C}$ with the continuous stirring. To remove noncollagenous proteins, the skin was mixed with $0.1 \mathrm{~N}$ $\mathrm{NaOH}$ at a sample/alkali solution ratio of $1: 10(\mathrm{w} / \mathrm{v})$ for $6 \mathrm{~h}$. The alkali solution was changed every $2 \mathrm{~h}$. Then, the protein free skin were washed with cold water until neutral or faintly basic $\mathrm{pH}$ of wash water were obtained. The protein free skins were defatted with $10 \%$ butyl alcohol with a solid/solvent ratio of $1: 10(\mathrm{w} / \mathrm{v})$ for $18 \mathrm{~h}$ and the solvent was changed every $6 \mathrm{~h}$. Defatted skins were washed with cold water, followed by soaking in $0.5 \mathrm{M}$ acetic acid with a 
solid/solvent ratio of $1: 30(\mathrm{w} / \mathrm{v})$ for $24 \mathrm{~h}$. The mixture was filtered. The residue was re-extracted under the same conditions. Both filtrates were combined. The collagen was precipitated by adding $\mathrm{NaCl}$ to a final concentration of $2.6 \mathrm{M}$ in the presence of 0.05 $\mathrm{M}$ tris(hydroxymethyl)aminomethane, $\mathrm{pH}$ 7.0. The resultant precipitate was collected by centrifuging at $4000 \mathrm{rpm}$ for $15 \mathrm{~min}$. The obtained pellet was dissolved in $0.5 \mathrm{M}$ acetic acid, dialysed against 0.1 $M$ acetic acid and distilled water, respectively, and then freeze-dried. The natural triple helix and fibrillary structure of the collagen were preserved during the extraction process.

\section{Preparation of collagen sheets}

Buffalo skin collagen was suspended in $0.5 \mathrm{M}$ acidic acid solution to prepare a $2.0 \%(\mathrm{w} / \mathrm{v})$ suspension. The collagen suspension was poured into a homemade Teflon mold, air dried at room temperature to obtain a porous collagen scaffold. After air-drying, the films were crosslinked with $10 \mathrm{ml}$ of GA solutions at different concentrations, in phosphate buffer at $\mathrm{pH} 7.4$ for $24 \mathrm{~h}$ at room temperature. The GA concentrations were $2.0 \%$ to $5 \%(\mathrm{w} / \mathrm{w})$. The cross-linked samples were then repeatedly washed with double distilled water and air dried at room temperature.

\section{Collagen Characterization}

For amino acid analysis freeze dried, collagen samples were hydrolysed with $6 \mathrm{M} \mathrm{HCl}$ for $22 \mathrm{~h}$ at $110^{\circ} \mathrm{C}$, dried under vacuum and dissolved in $10 \mathrm{mM} \mathrm{HCl}$. The amino acid mixture was injected into an amino acid auto analyzer (Amino acid analyzer 835, Hitachi Co., Japan).

FTIR measurements were carried out using attenuated total reflection Fourier transform infrared (ATR-FTIR) Spectrometer, Bruker, Germany. The FTIR spectra of the collagen were obtained in the spectral range from 4000 to $400 \mathrm{~cm}^{-1}$. The infrared beam enters the ATR germanium crystal at an angle of $45^{\circ}$ and is totally reflected at the crystal to sample interface.

Raman spectra of collagen was obtained using a spectrometer (BRUKER) with a double monochromator. An argon laser was applied with excitation at $514 \mathrm{~nm}$ with power up to $100 \mathrm{~mW}$. Scan speed was $50 \mathrm{~cm}^{-1} / \mathrm{min}$, spectral slit width was 500 $\mu \mathrm{m}$. The present dust fall samples were analyzed using a SEM (Model Philips XL 30) interfaced with energy dispersive X-ray analysis system and $\mathrm{Si}(\mathrm{Li})$ detector operated at accelerating voltage $30 \mathrm{kV}$.

Differential scanning calorimetry (DSC) was used to determine the thermal stability of the collagen samples. Collagen samples were rehydrated by adding deionized water to dried samples at a solid/ water ratio of 1:40 (w/v). The mixtures were allowed to stand for 12 hours at $4^{\circ} \mathrm{C}$. DSC was performed using a differential scanning calorimeter (Perkin Elmer, Model DSC7, Norwalk, CA). Temperature calibration was run using the Indium thermogram. The samples were accurately weighed into aluminum pans and sealed. The samples were scanned at $4{ }^{\circ} \mathrm{C} /$ min over the range of $-10-100^{\circ} \mathrm{C}$ using liquid nitrogen as the cooling medium. An empty pan was used as a reference.

Mechanical tests were performed on small pieces of $10 \mathrm{~mm} \times 30 \mathrm{~mm}$ with about $0.5 \mathrm{~mm}$ thickness, an Instron mechanical testing machine, with a crosshead speed of $5 \mathrm{~mm} / \mathrm{min}$. The Young's modulus $E$ (Elastic modulus), the stress at break $\sigma_{\mathrm{b}}$ (Strength at break) and the strain at break $\epsilon_{b}$ (Elongation at break \%) of the strips were measured.

\section{RESULT AND DISCUSSION}

\section{Yield}

Fig. 1, shows picture of extracted collagen after precipitation and before dialyses against 0.1 $M$ acetic acid and distilled water. Acid solubilized collagen was extracted from the skin of buffalo with the yield of $1.8 \%$ (based on wet weight of skin). The low yield imply that, the skin was not completely solubilised with $0.5 \mathrm{M}$ acetic acid even with two repetitions of extraction. This result was in agreement with Jongjareonrak ${ }^{31}$ who reported the incomplete solubilisation of bigeye snapper skin in $0.5 \mathrm{M}$ acetic acid. The yields of acid solubilised collagen from bigeye snapper skin were 1.1\% (wet weight basis) ${ }^{32}$. This result suggested a high amount of cross-links at the telopeptide region as well as other inter-molecular cross-links, leading to low solubility of collagen in acid. The presence of crosslinks was more likely associated with the tough skin ${ }^{9}$. Fig. 2, shows optical microscope image (100x) 
of collagen after freeze-drying. Fig. 3, show the SEM microstructure of freeze-dried native collagen. The collagen exhibits homogenous multi-layered aggregated, fibrillary structures. the collagen has an intensive, orderly and highly porous structure, the pores are interconnection, which is similarly beneficial to the cell adhesion and proliferation. This SEM image is similar to that obtained by crosslinked collagen from bovine tendon ${ }^{33}$. The result indicate that the buffalo skin collagen was suitable for the cell adhesion and proliferation without need of further crosslinking modification due to the appropriate porosity and pore size.

\section{Amino acid compositions}

The amino acid composition of buffalo skin collagen was expressed as residues per 1000 total

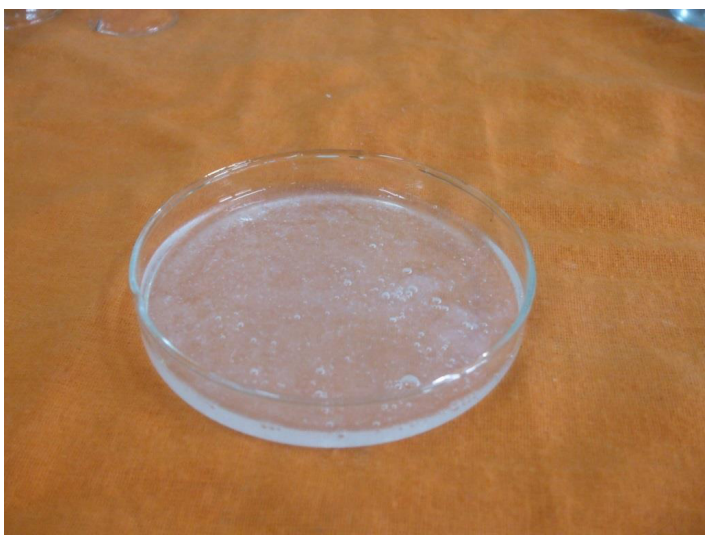

Fig. 1: Picture of acid-soluble buffalo skin collagen after desalting

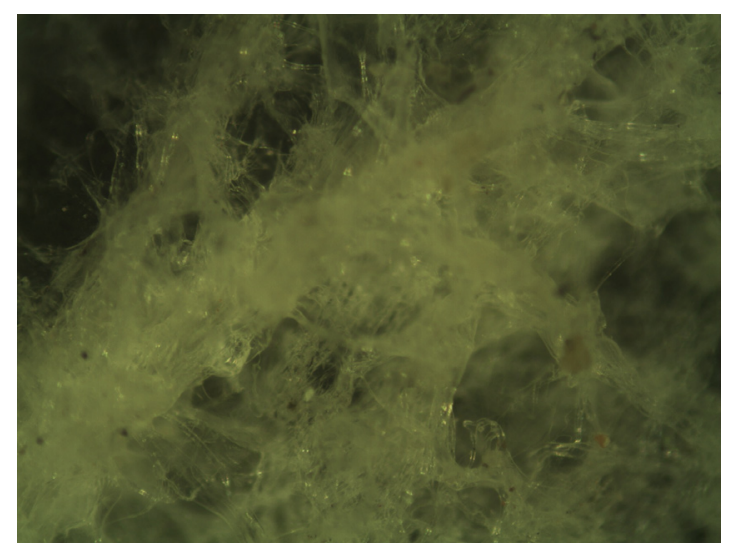

Fig. 2: Optical microscope picture of acidsoluble buffalo skin collagen after freeze drying (200X) amino acid residues are shown in Table 1. Compared with the analysis result of pure type I collagen (calf skin) ${ }^{34}$, the amino acid composition profile of buffalo skin collagen is similar to the former. Glycine is the major amino acid in both collagens. In general, glycine occours uniformly at every third residue throughout most of collagen molecules as a typical example of collagen of type I. Alanine was found as the second abundant amino acid. No cysteine was found in buffalo skin collagen. Generally, type I collagen has low amounts of cysteine ( $\sim 2$ residues per 1000 amino acids residues) ${ }^{35}$. The stabilization of conformation requires the occurrence of glycine residues at one of every three position in specific amino acid sequence of peptide chain. The contents of proline and hydroxyproline may be important for structural integrity of collagen. The proportions of hydroxyproline and proline residues in buffalo skin collagen are 97 and 128 residues per 1000 amino acids residues, respectively. The imino acid content (hydroxyproline and proline) of buffalo skin collagen was 225 residues/1000 residues, while calf skin collagen contained 215 residues/1000 residues. Therefore, buffalo skin had the higher imino acid content than calf skin collagens. Generally, the stabilizing of collagen triple helix depends on the contents of hydroxyproline residue. The results suggested that buffalo skin collagen might have higher thermal stability than calf skin collagen.

\section{FTIR spectroscopy}

Fourier transform infrared (FTIR) spectroscopy was conducted on type I collagen

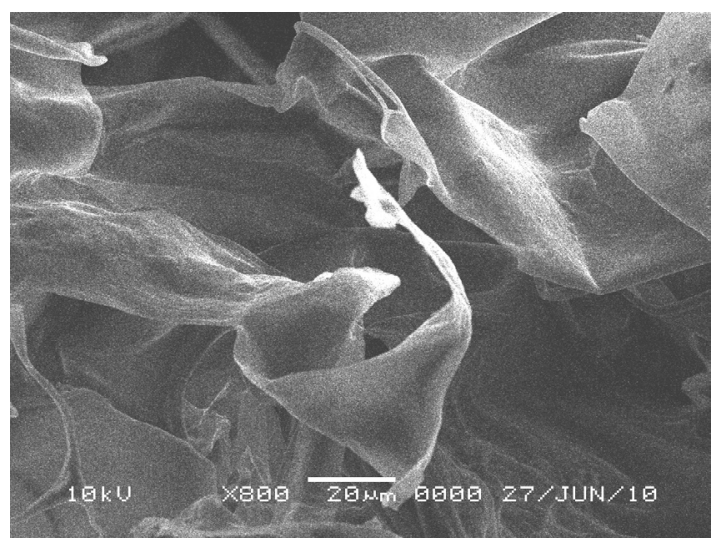

Fig. 3: SEM of acid-soluble buffalo skin collagen after freeze drying 
Table 1: Amino acid composition of buffalo skin collagen compared with calf $\mathbf{s k i n}^{34}$ collagen (expressed as residues/1000 residues)

\begin{tabular}{lcc}
\hline Amino acids & $\begin{array}{c}\text { Buffalo skin } \\
\text { collagen }\end{array}$ & $\begin{array}{c}\text { Calf skin } \\
\text { collagen }\end{array}$ \\
\hline Aspartic acid/Asparagine & 43 & 45 \\
Threonine & 19 & 18 \\
Serine & 31 & 33 \\
Glutamic acid/Glutamine & 76 & 75 \\
Glycine & 332 & 330 \\
Alanine & 112 & 119 \\
Cysteine & 0 & - \\
Valine & 23 & 21 \\
Methionine & 4 & 6 \\
Isoleucine & 12 & 11 \\
Leucine & 19 & 23 \\
Tyrosine & 4 & 3 \\
Phenylalanine & 9 & 3 \\
Hydroxylysine & 5 & 7 \\
Lysine & 25 & 26 \\
Histidine & 6 & 5 \\
Arginine & 51 & 50 \\
Tryptophan & 2 & - \\
Hydroxyproline & 97 & 94 \\
Proline & 128 & 121 \\
imino acids & 225 & 215 \\
\hline
\end{tabular}

extracted from skin of buffalo, as shown in Fig. 4. FTIR spectroscopy commonly, used to study the secondary structure of collagen. The spectrum were similar to those of collagen from other animals ${ }^{36-38}$ and shows typical bands of type I collagen. These include the main absorption bands of amide A (3299 $\left.\mathrm{cm}^{-1}\right)$, amide B (2950-2919 $\left.\mathrm{cm}^{-1}\right)$, amide I (1628 $\left.\mathrm{cm}^{-1}\right)$, amide II $\left(1540 \mathrm{~cm}^{-1}\right)$ and amide III $\left(1234 \mathrm{~cm}^{-1}\right)$. According to Doyle et al. ${ }^{39}$, a free $\mathrm{N}-\mathrm{H}$ stretching vibration occurs in the range of $3400-3440 \mathrm{~cm}^{-1}$ and when the $\mathrm{NH}$ group of a peptide is involved in a hydrogen bond, the position is shifted to lower frequencies, usually around $3300 \mathrm{~cm}^{-1}$. The result indicated that the $\mathrm{NH}$ groups of this collagen were involved in hydrogen bonding, probably with a carbonyl group of the peptide chain. The amide $\mathrm{B}$ band positions were found at wavenumbers of $2919 \mathrm{~cm}^{-1}$, representing the asymmetrical stretch of $\mathrm{CH}_{2}{ }^{40}$. Amide I peak $\left(1628 \mathrm{~cm}^{-1}\right)$ is associated with stretching vibrations of carbonyl groups $(\mathrm{C}=\mathrm{O}$ bond), along the polypeptide backbone ${ }^{41}$ and it is the most useful for infrared spectroscopic analysis of the secondary structure of proteins $\mathrm{s}^{42}$. The amide Il peak of the collagens was observed at $1540 \mathrm{~cm}^{-1}$, resulting from $\mathrm{N}-\mathrm{H}$ bending vibration coupled with the stretching vibration of $\mathrm{CN}\left(1536-1544 \mathrm{~cm}^{-1}\right){ }^{43}$. Amide III $\left(1234 \mathrm{~cm}^{-1}\right)$ is related to $\mathrm{CN}$ stretching and $\mathrm{NH}$ and is involved with the triple helical structure of collagen. Therefore, the FTIR investigations show the existence of helical arrangements of buffalo skin collagen.

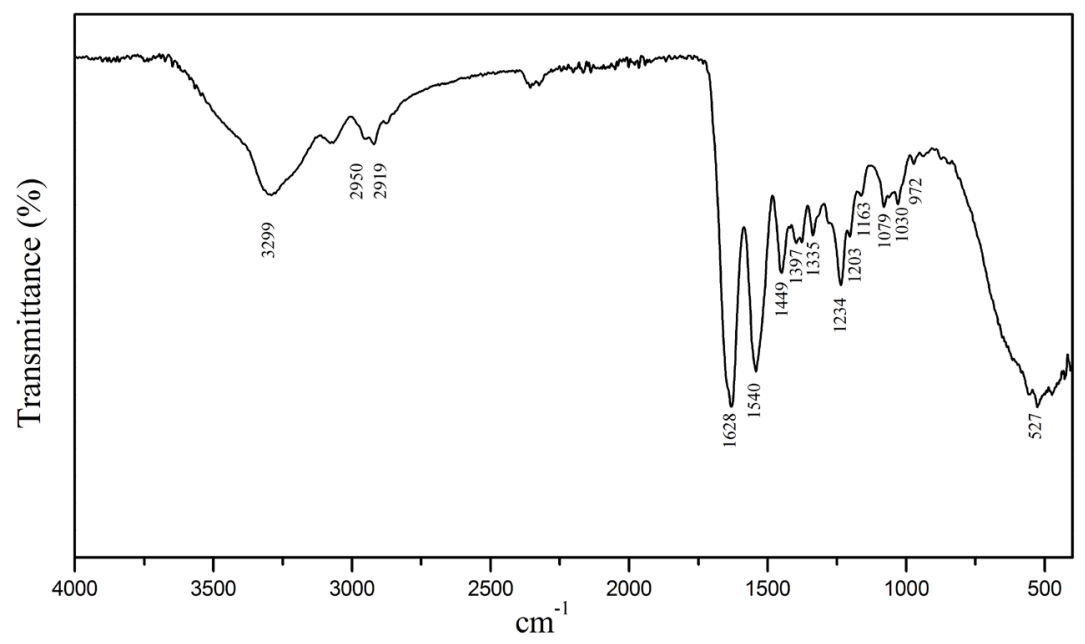

Fig. 4: ATR-FTIR spectrum of acid-soluble buffalo skin collagen 


\section{Raman spectrum}

Fig. 5, shows Raman spectra of native buffalo skin type I collagen. A peptide bond gives rise to many different types of vibrational modes, among which amide I (1672 $\left.\mathrm{cm}^{-1}\right)$ and amide III (1239 $\left.\mathrm{cm}^{-1}\right)$ bands are perfectly seen in Raman spectra ${ }^{44}$. The main contribution to the amide I band is the peptide carbonyl stretching vibration, whereas the amide III band originates from the $\mathrm{NH}$ in plane deformation at $1239 \mathrm{~cm}^{-1}$ coupled to the CN stretching mode at 1245 $\mathrm{cm}^{-1}$. Raman investigation is in good agreement with FTIR and amino acid analysis.

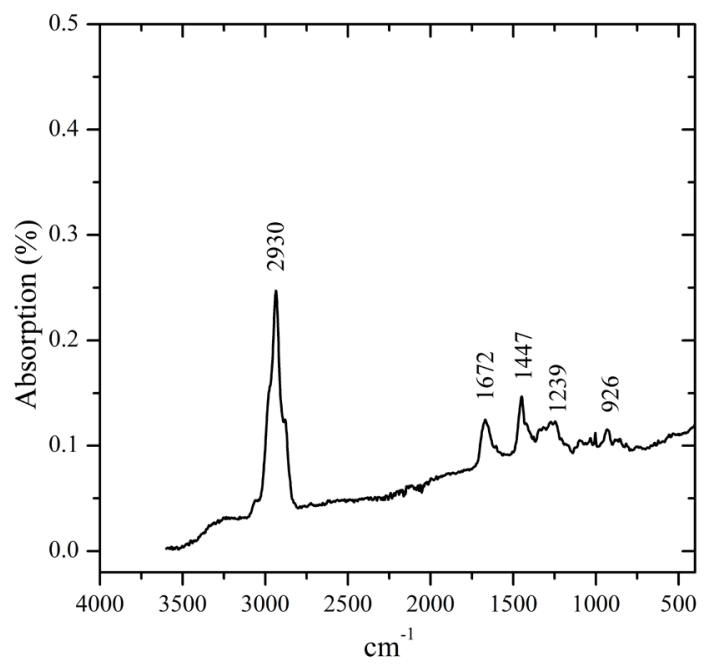

Fig. 5: Raman spectrum of acid-soluble buffalo skin collagen

\section{UV-Vis absorption spectrum}

Fig. 6 shows the UV-Vis. absorption spectrum of buffalo skin collagen at the wavelengths 200-400 $\mathrm{nm}$. Most proteins have a maximum ultraviolet absorption at $280 \mathrm{~nm}$ due to the number of tyrosine and tryptophan residue. The collagen in the present study contain 4 and 2 residue/1000 residue of tyrosine and tryptophan respectively. The collagen isolated from buffalo skin showed a maximum absorption at $231 \mathrm{~nm}$ and a broad band centered at $267 \mathrm{~nm}$. The band at $320 \mathrm{~nm}$ is similar to those of collagen from squid skin ${ }^{45}$. The band

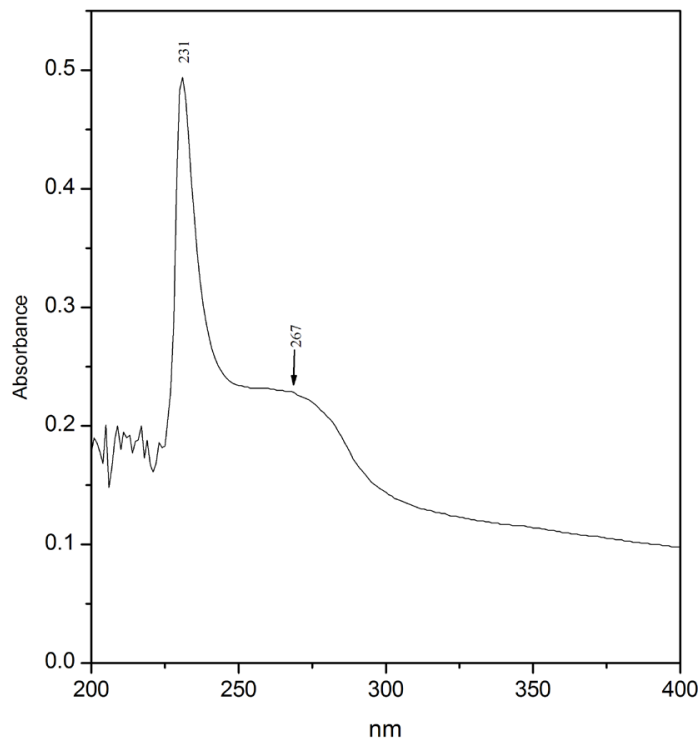

Fig. 6: UV-Vis spectrum of acid-soluble collagen from buffalo skin

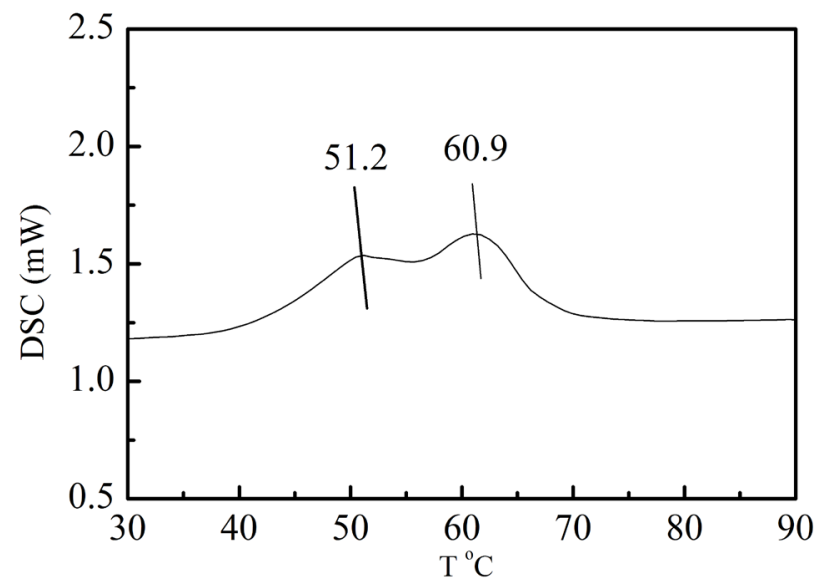

Fig. 7: DSC curve of acid-soluble type I collagen from buffalo skin 
Table 2: Mechanical properties of uncross-linked and cross-linked collagen

\begin{tabular}{lccc}
\hline $\begin{array}{l}\text { Type of } \\
\text { collagen }\end{array}$ & $\begin{array}{c}\text { Elastic } \\
\text { modulus (MPa) }\end{array}$ & $\begin{array}{c}\text { Strength at } \\
\text { break (MPa) }\end{array}$ & $\begin{array}{c}\text { Elongation at } \\
\text { break (\%) }\end{array}$ \\
\hline Collagen & 0.356 & 0.213 & 12 \\
Collagen +2\% GA & 0.267 & 0.315 & 15 \\
Collage + 5\% GA & 0.254 & 0.334 & 14 \\
\hline
\end{tabular}

at $230 \mathrm{~nm}$ is attributed to $n \rightarrow n^{*}$ transition of $\mathrm{C}=0$ in the polypeptides chains of collagen ${ }^{46}$. In $n \rightarrow n^{*}$ transition, the lone pair electron density on oxygen atom of peptide bond is transferred to antibonding orbital of the carbonyl of the subsequent peptide bond ${ }^{47}$. The band at $276 \mathrm{~nm}$ is due to chromophores groups of tyrosine and phenylalanine amino acid resides. The results indicate that the protein is collagen

\section{Denaturation temperature}

The collagen triple helix is formed of three molecular strands. The prolines are arranged in a left handed polyproline-II-helical conformation, and these helices coil together to form a right handed super helix. When collagen is heated above its denaturation temperature $\left(T_{d}\right)$ the triple helical structure of collagen can transform into random $\mathrm{coil}^{48}$. Lower denaturation temperature (lower thermal stability) is one of the main drawbacks for the biomedical application of collagens. Fig. 7, shows DSC curve of acid-soluble type I collagen from buffalo skin. Analysis of differential scanning calorimetry revealed that thermal denaturation of buffalo skin collagen occurs in two steps at $51.2{ }^{\circ} \mathrm{C}$ and $60.9^{\circ} \mathrm{C}$. Both the temperatures were much higher than the $T_{m}$ of calf skin collagen $\left(40.8^{\circ} \mathrm{C}\right)^{49}$ and the $\mathrm{T}_{\mathrm{d}}$ of pig skin collagen $\left(37^{\circ} \mathrm{C}\right)^{50}$. Triple helical structure of collagen molecule is more stable with higher imino acid content (proline and hydroxyproline) as these facilitate intra- and inter-molecular crosslinking. The higher the proline content, the more stable are the triple helices structure, because the molecular structure of collagen is maintained mainly by restrictions on changes in the secondary structure of the polypeptide chain, imposed by the pyrrolidine rings of proline ${ }^{51}$. The present buffalo skin collagen has higher proline content (128 residues per
1000 residues) than both calf skin collagen (121 residues per 1000 residues) and pig skin collagen (123 residues per 1000 residues $)^{51}$ so denatures at higher temperature. Moreover, hydroxyproline may stabilize the triple helix by the hydrogen bonds, as originally proposed by Ramachandran et al..$^{52}$ Buffalo skin collagen has higher hydroxyproline content (97 residues per 1000 residues) than calf skin collagen (94 residues per 1000 residues). Due to high denaturation temperature Buffalo skin collagen is suitable for deferent biomedical applications.

\section{Mechanical properties}

Tensile stress-strain analysis was performed on buffalo collagen matrices with 0,2 and $5 \%$ glutaraldehyde as cross-linking reagent. The results of elastic modulus, strength at break and elongation at break of collagen scaffold strips and collagen scaffold strips treated with two different concentration of glutaraldehyde are presented in table 2. It is clear from the results that the stiffness of collagen scaffold increase with addition of glutaraldehyde due to increase in degree of crosslinking ${ }^{53}$.

\section{CONCLUSIONS}

This study investigated the characteristics of acid-extracted collagen from buffalo skin with the methods of amino acid analysis, ATR-FTIR, Raman, SEM and DSC. The collagen can be classified as type I collagen according to the results and analysis of amino acid composition, Raman and FTIR. It has a distinct amino acid composition and thermal stability, different from those of calf skin collagen. FTIR investigations show the existence of helical arrangements of collagen. The high thermal stability of buffalo skin collagen with respect to calf skin collagen is due to its high contents of porline 
amino acid resides. The stiffness of collagen scaffold increases after cross-linking with glutaraldehyde. Therefore, the results suggest that collagen of buffalo skin should be a potential resource alternative to pig and calf collagen for food, cosmetic, biomedical and pharmaceutical applications.

\section{ACKNOWLEDGEMENTS}

This work was funded by Deanship of Scientific Research at Najran University, Saudi Arabia, Research Code: NU/ESCI/14/034

\section{REFERENCES}

1. Martínez-Ortiz, M. A.; Hernández-Fuentes, A. D.; Pimentel-González, D. J.; CamposMontiel, R. G.; Vargas-Torres, A.; AguirreÁlvarez, G. CyTA-Journal of Food 2015, 13, 253-258.

2. García-Gareta, E.; Coathup, M. J.; Blunn, G. W. Bone 2015, 81, 112-121.

3. Brinckmann, J. Top Curr Chem 2005, 274, 1-6.

4. Veit, G.; Kobbe, B.; Keene, D. R.; Paulsson, M.; Koch, M.; Wagener, R. Journal of Biological Chemistry 2006, 281, 3494-3504.

5. Chan, K. L.; Khankhel, A. H.; Thompson, R. L.; Coisman, B. J.; Wong, K. H.; Truslow, J. G.; Tien, J. Journal of Biomedical Materials Research Part A 2014, 102, 3186-3195.

6. Di Summa, P. G.; Kingham, P. J.; Campisi, C. C.; Raffoul, W.; Kalbermatten, D. F. Neuroscience letters 2014, 572, 26-31.

7. Zhu, L.; Wen, D. J. Soochow Univ. Eng. Sci. Ed. 2008, 28, 63-66.

8. Abedin, M. Z.; Karim, A. A.; Latiff, A. A.; Gan, C.-Y.; Ghazali, F. C.; Barzideh, Z.; Ferdosh, S.; Akanda, M. J. H.; Zzaman, W.; Karim, M. R. Natural product research 2014, 28, 13021305.

9. Ahmad, M.; Benjakul, S. Food Chemistry 2010, 120, 817-824.

10. Mokrejs, P.; Langmaier, F.; Mládek, M.; Janacova, D.; Kolomazník, K.; Vasek, V. Waste Management \& Research 2009, 27, 31-37.

11. Dupont-Gillain, C. C. Colloids and Surfaces B: Biointerfaces 2014, 124, 87-96.

12. Elias, P. Z.; Spector, M. Journal of tissue engineering and regenerative medicine 2015, 9, 137-150.

13. Sadeghi ${ }^{1}$, M.; Yarahmadi, M. Oriental Journal of Chemistry 2011, 27, 453-460.

14. Heinemann, F.; Hasan, I.; Schwahn, C.; Bourauel, C.; Mundt, T. Annals of Anatomy-
Anatomischer Anzeiger 2012, 194, 508512.

15. Helary, C.; Abed, A.; Mosser, G.; Louedec, L.; Letourneur, D.; Coradin, T.; Giraud-Guille, M. M.; Meddahi-Pellé, A. Biomaterials science 2015, 3, 373-382.

16. Ali, M. Y.; Chuang, C.-Y.; Saif, M. T. A. Soft matter 2014, 10, 8829-8837.

17. Borde, B.; Grunert, P.; Härtl, R.; Bonassar, L. J. Journal of Biomedical Materials Research Part A 2015, 103, 2571-2581.

18. Jabaji, Z.; Brinkley, G. J.; Khalil, H. A.; Sears, C. M.; Lei, N. Y.; Lewis, M.; Stelzner, M.; Martín, M. G.; Dunn, J. C. PloS one 2014, 9, e107814.

19. Kuroyanagi, M.; Yamamoto, A.; Shimizu, N.; Ishihara, E.; Ohno, H.; Takeda, A.; Kuroyanagi, Y. Journal of Biomaterials Science, Polymer Edition 2014, 25, 1133-1143.

20. Kawai, T.; Echigo, S.; Matsui, K.; Tanuma, Y.; Takahashi, T.; Suzuki, O.; Kamakura, S. Tissue Engineering Part A 2014, 20, 13361341.

21. Alghamdi, H. S.; Bosco, R.; van den Beucken, J. J.; Walboomers, X. F.; Jansen, J. A. Biomaterials 2013, 34, 3747-3757.

22. Kim, J. W.; Jeong, I. H.; Lee, K. I.; Jung, U. W.; Kim, C. S.; Choi, S. H.; Cho, K. S.; Yun, J. H. Journal of Biomedical Materials Research Part A 2013, 101, 1223-1223.

23. Inzana, J. A.; Olvera, D.; Fuller, S. M.; Kelly, J. P.; Graeve, O. A.; Schwarz, E. M.; Kates, S. L.; Awad, H. A. Biomaterials 2014, 35, 40264034.

24. Nair, L. S.; Laurencin, C. T. Progress in polymer science 2007, 32, 762-798.

25. Kikuchi, M.; Matsumoto, H. N.; Yamada, T.; Koyama, Y.; Takakuda, K.; Tanaka, J. Biomaterials 2004, 25, 63-69.

26. Sheu, M.-T.; Huang, J.-C.; Yeh, G.-C.; Ho, H.-O. Biomaterials 2001, 22, 1713-1719. 
27. Bishop, P.; McLeod, D.; Ayad, S. Biochemical and biophysical research communications 1992, 185, 392-397.

28. Gómez, K. K.; Del Prado, M. L.; Piña, M. C.; de León, M. C. G. In MEDICAL PHYSICS: Twelfth Mexican Symposium on Medical Physics; AIP Publishing: 2012; Vol. 1494, p 149-151.

29. Jin, Y.; Xu, S.-y.; Liu, Z.-h. Fine ChemicalsDalian- 2001, 18, 302-304.

30. Kukhareva, L.; Shamolina, I.; Polevaia, E. Tsitologiia 2009, 52, 597-602.

31. Jongjareonrak, A.;Benjakul, S.;Visessanguan, W.; Tanaka, M. Journal of the Science of Food and Agriculture 2005, 85, 1203-1210.

32. Jongjareonrak, A.;Benjakul, S.;Visessanguan, W.; Nagai, T.; Tanaka, M. Food Chemistry 2005, 93, 475-484.

33. Liu, S.; Xie, R.; Cai, J.;Wang, L.; Shi, X.; Ren, L.; Wang, Y. RSC Advances 2015, 5, 4608846094.

34. Giraud-Guille, M.-M.; Besseau, L.; Chopin, C.; Durand, P.; Herbage, D. Biomaterials 2000, 21, 899-906.

35. Owusu-Apenten, R. Food protein analysis: quantitative effects on processing; CRC Press, 2002; Vol. 118.

36. Takeshi, N.; Nobutaka, S.; Yasuhiro, T.; Norihisa, K.; Toshio, N. Food and Nutrition Sciences 2010, 1, 59-66.

37. Takeshi, N.; Nobutaka, S.; Yasuhiro, T.; Norihisa, K. Food and Nutrition Sciences 2012, 3, 72-79.

38. Wu, G. P.; Wang, X. M.; Lin, L. P.; Chen, S. $\mathrm{H}$.; Wu, Q. Q. Advances in Bioscience and Biotechnology 2014, 5, 642-650.
39. Doyle, B.B.;Bendit, E.;Blout, E. R. Biopolymers 1975, 14, 937-957.

40. Muyonga, J.; Cole, C.; Duodu, K. Food Chemistry 2004, 86, 325-332.

41. Eklouh-Molinier, C.; Sebiskveradze, D.; Feru, J.; Terryn, C.; Manfait, M.; Brassart-Pasco, S.; Piot, O. Analyst 2014, 139, 2482-2488.

42. Surewicz, W. K.; Mantsch, H. H. Biochimica et Biophysica Acta (BBA)-Protein Structure and Molecular Enzymology 1988, 952, 115-130.

43. Krimm, S.; Bandekar, J. Advances in protein chemistry 1986, 38, 181-364.

44. Shepherd, D.; Shepherd, J.; Ghose, S.; Kew, S.; Cameron, R.; Best, S. APL materials 2015 , 3, 014902 014901-014908.

45. Veeruraj, A.; Arumugam, M.; Ajithkumar, T.; Balasubramanian, T. Food Hydrocolloids 2015, 43, 708-716.

46. G. He, Y. Y., L. Meng, L. Yan, Q. Yu Nongye Jixie Xuebao 2010, 41 124-128.

47. Shoulders, M. D.; Raines, R. T. Annual review of biochemistry 2009, 78, 929-958.

48. Muyonga, J.; Cole, C.; Duodu, K. Food Chemistry 2004, 85, 81-89.

49. Komsa-Penkova, R.; Koynova, R.; Kostov, G.; Tenchov, B. Biophysical Chemistry 2000, 83, 185-195.

50. rNagai, T.; Suzuki, N. Food Chemistry 2002, 76, 149-153.

51. Zhang, Y.; Liu, W.; Li, G.; Shi, B.; Miao, Y.; Wu, X. Food chemistry 2007, 103, 906-912.

52. Ramachandran, G.; Bansal, M.; Bhatnagar, R. Biochimica et Biophysica Acta (BBA)-Protein Structure 1973, 322, 166-171.

53. Grover, C. N.; Cameron, R. E.; Best, S. M. Journal of the mechanical behavior of biomedical materials 2012, 10, 62-74. 